\title{
THE EFFECT OF THE USE OF DIFFERENT COVER MATERIALS ON HEAT TRANSFER IN FLAT SOLAR COLLECTORS
}

\author{
Mesut Tekkalmaz ${ }^{1}$, Çisil Timuralp ${ }^{1}$, Zerrin Sert $^{1, *}$
}

\begin{abstract}
In this study, combined thermal radiation and natural convection heat transfer from glass and plastic cover flat solar collectors is examined by varying tilt angle and cover materials. The flat-plate solar collector tilt angle is varied from $0^{\circ}$ to $45^{\circ}$. The performance of glass, lexan, and acrylic cover materials is investigated. Numerical simulations have been performed for various solar collector thicknesses exposed to external ambient temperature and wind heat transfer coefficient. Continuity, momentum and the energy equations, along with the Boussinesq approach, are solved with the finite volume method using the SIMPLE algorithm. The cover temperature and the top loss coefficient are calculated for each cover material, collector tilt angle and bottom plate temperature, wind heat transfer coefficient and external ambient temperature. The flow and temperature field are obtained, and the mean convection and radiation Nusselt numbers are calculated for the bottom plate. The analytically and numerically computed glass cover temperatures are found to be in perfect agreement. The top loss coefficient of the plastic cover is lower than that of the glass cover. It is determined that with increasing heat input from the bottom plate, the top loss coefficient and the mean cover material temperature increase linearly. As the external ambient temperature increases, the top loss coefficient and the cover material temperature do not present any significant change.
\end{abstract}

Keywords: Thermal Radiation, Natural Convection, Different Cover Materials, Flat-Plate, Solar Collector

\section{INTRODUCTION}

A solar collector's domestic applications are a flat plate, concentrating collectors or evacuated tube. A flat-plate collector (FPC), is a special kind of heat exchanger that transforms solar radiation energy into internal energy, which is transferred through a working liquid and is frequently used in industry. The FPCs should be easy to manufacture at low cost and have low thermal resistance for use in medium and low-temperature applications. Plastic solar collectors (PSCs) are one of these options. PSCs have been in use for many years in low-temperature applications, such as volume heating, swimming pool heating and drying [1-4].

In solar collectors, heat transfer lost is mostly observed in the cover material. Many studies regarding the top heat loss coefficient have been published in the literature. In Akhtar and Mullick's study [5], an approximate method for the computation of the glass cover temperature and top heat-loss coefficient of solar collectors with single glazing is investigated. They [6] also study the effects of the absorption of solar radiation on inner and outer surface temperatures and, consequently, on convective and radiative heat transfer coefficients over a wide range of independent variables. They develop correlations and the results indicate that solar absorption in a glass cover increases glass temperature under steady-state analysis. An empirical equation for glass cover temperature and top heat loss coefficient of a single glazed FPC with vertical configuration was developed by Kumar and Mullick [7]. In FPC with double glazing, the analytical equation for top heat loss is given by Samdarshi and Mullick [8].

When determining a solar collector's performance, there are several other parameters that should be considered other than just cover material selection. These are air gap spacing, environmental conditions, collector tilt angle and suchlike. There have also been studies investigating these parameters in the literature. The impact of the thickness of the air gap between the solar collector and the glass on convection loss has been studied by Ferahta et al [9]. Subiantoro and Tiow [10] simulate analytical models for the computation and optimization of single and double glazing FPC with normal and small air gap spacing. They find that the optimal gap in single and double glazing used on solar collectors is around $10 \mathrm{~mm}$. In FPC, heat loss caused by wind has a significant effect and this is why the wind heat transfer coefficient is required to find heat losses from the outer This paper was recommended for publication in revised form by Regional Editor Ozgen Acikgoz

${ }^{1}$ Department of Mechanical Engineering, Eskisehir Osmangazi University, Eskisehir, Turkey

*E-mail address: zbocu@ogu.edu.tr

Orcid id: 0000-0003-3781-0384, 0000-0002-2894-3575, 0000-0001-6934-5443

Manuscript Received 25 October 2018, Accepted 29 March 2019 
surface. Kumar and Mullick [11] employ an unglazed test plate to estimate the wind-induced convection heat transfer coefficient in outdoor conditions. Hematian and Bakhtiari [12] evaluate the thermal efficiency of an air solar plate collector in different convection modes. It is concluded that, compared with forced convection, the collector provides higher efficiency in natural convection. However, the heat loss in natural convection is also considerably higher than forced convection. Wu et. al. [13], investigate the convection heat transfer characteristics of a flat plate under environmental wind conditions experimentally and they develop new correlations. A theoretical study for predicting the optimum tilt angle for FPCs throughout the world is presented by Stanciu and Stanciu [14]. They conclude that the optimum tilt angle for a FPC should be computed as a function of latitude and declination. Jiandong et al [15] studied the thermal efficiency of a flat plate solar collector by changing the collector tube spacing, length, diameter, thickness of absorber plate and insulation. Aravindh and Sreekumar [16] present a review of modifications of an absorber plate for effective efficiency in solar air heaters.

The radiation of semi-transparent wall (cover material) plays an important role in heat transfer and air flow inside the enclosure. However, the literature pays less attention to the influence of different semitransparent cover materials using the solar plate collector. Equations for the radiative heat transfer in an absorber plate and the transparent plastic covered solar air heater have been studied by Jannot and Coulibaly [17]. Khoukhi and Maruyama [18] studied radiation in glazing systems for solar collectors, including the convective heat transfer between glass cover and absorber. They report that wind speed on the glass cover temperature is important for the mean absorber temperature and they also compare external heat transfer with radiative heat transfer for different incident radiation. El-Sebaii and Al-Snani [19] present the effect of solar radiation intensity, dimensions of the absorber on the flowing air outlet temperature and coating materials of the absorber plate. They selected black paint, $\mathrm{CuO}, \mathrm{Cr}-\mathrm{Cr}_{2} \mathrm{O}_{3}, \mathrm{Ni}-\mathrm{Sn}$ and $\mathrm{CuO}$ as coating materials. When the absorber is coated with Ni-Sn and the surface is painted black, the total energy loss in Ni-Sn is reduced by $30 \%$ while the useful energy rate increases by $31 \%$. Alghoul et. al. [20] researched the materials used for solar thermal collectors. The effect of low emissivity glass covers used in single-glazed and double-glazed flat collectors are presented by Giovannetti et. al. [21].

In recent years, the use of nanoparticles as solar absorbers in solar collectors has increased because of their thermal properties. Otanicar et. al. [22] conducted an experimental study concerning nanofluid based on direct absorption solar collectors and compared their results with numerical results. Their study shows that efficiency is increased by $5 \%$ compared to the base fluid adding nanoparticles. The use of carbon nanotubes nanofluid in a direct absorption solar collector is investigated by Karami et. al. [23]. Ahlatli et. al. [24] studied the thermal performance of carbon nanotube nanofluids in solar microchannel collectors experimentally. The results demonstrate an initial rapid increase in heat transfer using nanofluids. This increase is even greater when the weight fraction of the nanofluids increased. Roy et. al. [25] investigated experimentally the heat transfer characteristics of silver/water nanofluid in a solar flat plate collector. They concluded that an increase in the performance of nanofluid is also witnessed when compared to the base fluid, which has a strong dependency on volume concentration and mass flow rate. Hussein et. al. [26] given a comprehensive overview about the recent advances related with the application of the nanotechnology in the direct absorption solar collectors.

There are many types and shapes of plastic, including sheets and film. Plastics are used for a wide range of current and potential applications in solar energy applications, such as covers, thin-film honeycombs, flatplate collectors, reflecting surfaces and optical lenses for concentrating collectors, reflector shells and suchlike. Plastics items require less maintenance than those produced from other materials. Therefore, in the field of solar applications, plastics are strong competitors with common traditional materials, such as glass, metals, and wood. Glass is the most-commonly used transparent cover. Low heat resistance, brittleness, and higher density are the negative characteristics of glass. In addition, as glass absorbs heat, losses to the atmosphere increase. The use of plastic covers instead of transparent glass covers is an alternative for these collectors. These plastic covers can be used as transparent covers because of their low density, resistance to breakage, ease of manufacture and high transmission of solar radiation.

Published studies in the literature show that glass covers are widely-used in solar collectors. In this study, two different plastic covers (lexan, and acrylic) are investigated separately and together with respect to the traditional glass cover. In addition, the effects of heat input from the absorber bottom plate and external ambient temperature, the effects of the wind heat transfer coefficient, collector tilt angle and air spacing gap change on 
the top loss coefficient are numerically investigated. Moreover, the effect of transmissivity and temperature drop of long-wave semi-transparent cover material is taken into consideration in calculations.

\section{MATHEMATICAL MODEL}

The geometry of a two-dimensional FPC considered in the combined heat transfer and the fluid flow is shown in Figure 1.

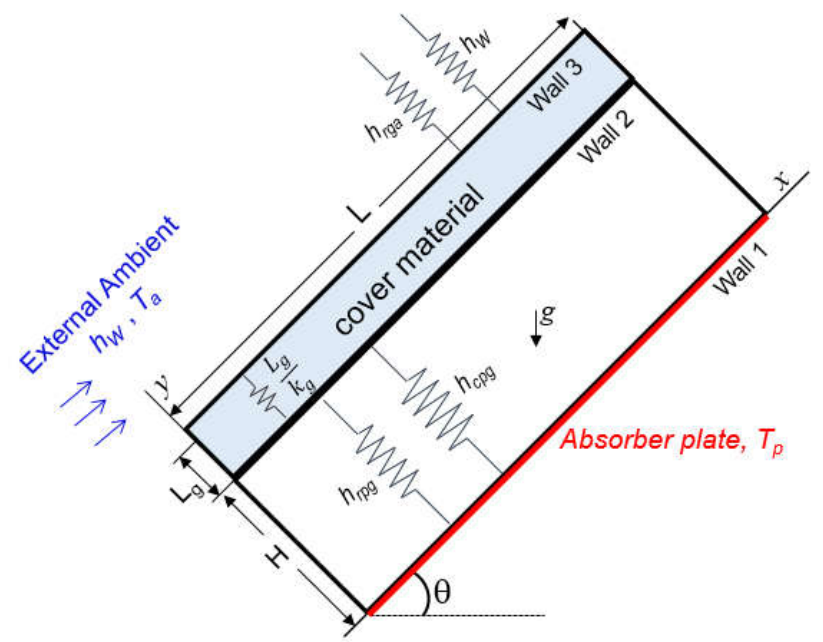

Figure 1. A physical model and coordinate system

The variables used in this parametric study, along with their upper and lower bounds, are provided in Table 1. The solar collector is filled with non-participating air $(\operatorname{Pr}=0.71)$. The bottom plate, in which sunlight is absorbed, is the only source of heat input and the collector tilt angle $(\theta)$ is taken as $0^{\circ}$ and $45^{\circ}$.

Table 1. The range of variables

\begin{tabular}{|c|c|}
\hline Variables & Range \\
\hline Air gap spacing, $\mathrm{H}$ & $10-90 \mathrm{~mm}$ \\
\hline Collector tilt angle, $\theta$ & $0^{\circ}$ and $45^{\circ}$ \\
\hline Wind heat transfer coefficient, $h_{w}$ & $5-45 \mathrm{~W} / \mathrm{m}^{2} \mathrm{~K}$ \\
\hline External ambient temperature, $T_{a}$ & $273-298 \mathrm{~K}$ \\
\hline Bottom plate temperature, $T_{p}$ & $323-423 \mathrm{~K}$ \\
\hline Surface emissivity, $\varepsilon_{\mathrm{w}}$ & 0.9 (for wall 1-2) \\
\cline { 2 - 2 } & 1 (for wall 3) \\
\hline
\end{tabular}

The governing equations mass, momentum and energy for two-dimensional steady-state, incompressible laminar flow and variation of density of the fluid is modeled by the Boussinesq approximation. Under these circumstances, the governing equations used in the present study can be written as follows:

Continuity equation:

$$
\frac{\partial u}{\partial x}+\frac{\partial v}{\partial y}=0
$$

$\mathrm{x}$-momentum equation:

$$
u \frac{\partial u}{\partial x}+v \frac{\partial u}{\partial y}=-\frac{1}{\rho} \frac{\partial P}{\partial x}+v\left(\frac{\partial^{2} u}{\partial x^{2}}+\frac{\partial^{2} u}{\partial y^{2}}\right)+g \beta \sin \theta\left(T-T_{0}\right)
$$


y-momentum equation:

$$
u \frac{\partial v}{\partial x}+v \frac{\partial v}{\partial y}=-\frac{1}{\rho} \frac{\partial P}{\partial y}+v\left(\frac{\partial^{2} v}{\partial x^{2}}+\frac{\partial^{2} v}{\partial y^{2}}\right)+g \beta \cos \theta\left(T-T_{0}\right)
$$

Energy equation:

$$
u \frac{\partial T}{\partial x}+v \frac{\partial T}{\partial y}=\alpha\left(\frac{\partial^{2} T}{\partial x^{2}}+\frac{\partial^{2} T}{\partial y^{2}}\right)
$$

The conduction heat transfer equation of the semi-transparent wall is given by [27]

$$
\nabla \cdot\left(k_{g} \nabla T\right)=\kappa\left(4 \pi I_{b}-G(\mathbf{r})\right)
$$

where $\beta$ is the thermal expansion coefficient, $\alpha$ is the thermal diffusivity coefficient, $v$ is the kinematic viscosity, $\mathrm{g}$ is the gravitational acceleration, $P$ is the pressure, $k$ is the thermal conductivity, $\rho$ is the density, $c_{p}$ is the specific heat capacity, $T$ is the temperature, $\kappa$ is the absorption coefficient, $G(\mathbf{r})$ is the incident energy, $I_{b}$ is the blackbody radiation intensity and the subscript of ' $\mathrm{g}$ ' is cover.

To calculate the radiative heat exchange, the radiative transfer equation (RTE) needs to be solved, as defined by [28]:

$$
\nabla \cdot(I(\mathbf{r}, \mathbf{s}) \mathbf{s})+\left(\kappa+\sigma_{s}\right) I(\mathbf{r}, \mathbf{s})=\kappa n^{2} \frac{\sigma T_{0}^{4}}{\pi}+\frac{\sigma_{s}}{4 \pi} \int_{0}^{4 \pi} I(\mathbf{r}, \mathbf{s}) \Phi\left(\mathbf{s} \cdot \mathbf{s}^{\prime}\right) d \Omega^{\prime}
$$

for a medium which is absorbing, emitting and scattering. In the preceding equation, $\mathbf{r}$ is the position vector, $\mathbf{s}$ is the direction vector, $\mathbf{s}^{\prime}$ is the direction vector of scattering, $\kappa$ is the absorption coefficient, $\sigma_{s}$ is scattering coefficient, $\sigma$ is the Stefan-Boltzmann constant, $I$ is the incident radiation, $\Omega^{\prime}$ is the solid angle, and $\Phi$ is the phase function.

The DOM (Discrete Ordinates Method) is used to solve the RTE (Eq. 6). Since the ambient air is nonparticipating, the absorption and scattering coefficients are taken as zero in this study. The incident energy in Eq. [5] is given by [28]:

$$
G(\mathbf{r})=\int_{4 \pi} I(\mathbf{r}, \mathbf{\Omega}) d \mathbf{\Omega}
$$

The boundary conditions are as follows; no-slip BC is used for the velocity components on the walls $(u=v=0)$, energy boundary conditions:

$$
\begin{aligned}
& \text { wall-1: } \quad T_{1}=T_{p} \\
& \text { wall-2: } \quad-k_{g} \frac{\partial T_{g, 2}}{\partial x}=-k \frac{\partial T}{\partial x}+q_{r, 2} \\
& \text { wall-3: } \quad h_{w}\left(T_{g, 3}-T_{a}\right)+\sigma \varepsilon_{g}\left(T_{g, 3}^{4}-T_{a}^{4}\right)=-k_{g} \frac{\partial T_{g, 3}}{\partial x} \\
& \text { the other walls: } \quad \frac{\partial T}{\partial y}=0
\end{aligned}
$$

The intensity of radiation in an outgoing direction from the opaque bottom wall (absorber plate, wall 1) is given as [28]: 


$$
I_{p}=\frac{1}{\pi}\left[\left(1-\varepsilon_{w}\right) \int_{\mathbf{s} \cdot \mathbf{n}>0} I_{i n} \mathbf{s} \cdot \mathbf{n} d \Omega+n_{a}^{2} \varepsilon_{w} \sigma T_{p}^{4}\right]
$$

The mixed boundary condition (forced convection and radiation) is taken into consideration in wall-3. Wall-2 is an interface between air and a semi-transparent cover. When the diffuse radiation fraction is equal to 1 , all of the transmitted and reflected radiant energy at the semi-transparent wall is purely diffuse. In such a case, the interfacial reflectivity $\mathrm{r}(\mathbf{s})$ is assumed independent of $\mathbf{s}$, and equal to the hemispherical averaged value $\mathrm{r}_{2}$. For $n=n_{g} / n_{a}>1, r_{2, g}$ and $r_{2, a}$ are given by [28]:

$$
\begin{gathered}
r_{2, g}=1-\frac{1-r_{2, a}}{n^{2}} \\
r_{2, a}=\frac{1}{2}+\frac{(3 n+1)(n-1)}{6(n+1)^{2}}+\frac{n^{2}\left(n^{2}-1\right)}{\left(n^{2}+1\right)^{3}} \ln \left(\frac{n-1}{n+1}\right) \\
-\frac{2 n^{3}\left(n^{2}+2 n-1\right)}{\left(n^{2}+1\right)\left(n^{4}-1\right)}+\frac{8 n^{4}\left(n^{4}+1\right)}{\left(n^{2}+1\right)\left(n^{4}-1\right)^{2}} \ln (n)
\end{gathered}
$$

The boundary intensity for all outgoing directions on the side cover of the interface is given by [28]:

$$
I_{2, g}=\frac{1}{\pi}\left[r_{2, g} q_{i n, g}+\tau_{2, a} q_{i n, a}\right]
$$

Similarly for side air,

$$
\begin{gathered}
I_{2, a}=\frac{1}{\pi}\left[r_{2, a} q_{i n, a}+\tau_{2, g} q_{i n, g}\right] \\
q_{i n, g}=-\int_{\mathbf{s}: \mathbf{\wedge}<0} I_{2, g} \mathbf{s} \cdot \mathbf{n} d \Omega \\
q_{i n, a}=\int_{\mathbf{s}: \mathbf{n}>0} I_{2, a} \mathbf{s} \cdot \mathbf{n} d \Omega
\end{gathered}
$$

The total mean Nusselt numbers are calculated by:

$$
N u_{t}=N u_{c}+N u_{r}=\frac{q_{c}+q_{r}}{k \Delta T / \mathrm{H}}
$$

Here, $q_{\mathrm{c}}$ and $q_{r}$ are the mean convection and radiation heat fluxes for the wall, respectively.

In the solar collector, the cover thickness $\left(\mathrm{L}_{\mathrm{g}}=3.2 \mathrm{~mm}\right)$ is investigated for glass, lexan, acrylic covers. The thermo-physical properties of the solar collector covers are given in Table 2.

Table 2. Thermo-physical properties of the solar collector cover material $[29,30,31]$

\begin{tabular}{|c|c|c|c|}
\hline & \multicolumn{3}{|c|}{ Cover Materials } \\
\hline Thermo-physical properties & Glass & Lexan & Acrylic \\
\hline Density, $\left(\mathrm{kg} / \mathrm{m}^{3}\right)$ & 2500 & 1200 & 1170 \\
\hline Specific heat capacity, $(\mathrm{J} / \mathrm{kgK})$ & 750 & 1250 & 1480 \\
\hline Thermal conductivity, $(\mathrm{W} / \mathrm{mK})$ & 1.4 & 0.2 & 0.201 \\
\hline Reflective index $\left(n_{g}\right)$ & 1.5 & 1.586 & 1.5 \\
\hline
\end{tabular}




\section{NUMERICAL PROCEDURE AND VALIDATION}

The governing momentum, energy and radiative transfer equations are discretized using the FVM, and the resulting equations are solved using an iterative procedure with standard implicit, second order upwind solver with velocity and pressure coupling achieved by the SIMPLE algorithm. In DOM, the radiation field is divided into a number of discrete directions. The computations are carried out using Fluent ${ }^{\mathbb{B}}$.

For validation, the current numerical model is compared with the analytical study of Akhtar and Mullick [5]. In order to determine the glass cover temperature, the ratio of the inner and outer heat transfer coefficients given by Akhtar and Mullick [5] is used. This function $f$ is given in Eq. (17):

$$
f=\frac{\left[12 \times 10^{-8}\left(T_{a}+0.2 T_{p}\right)^{3}+h_{w}\right]^{-1}+0.3 L_{g}}{\left[6 \times 10^{-8}\left(\varepsilon_{w, 3}+0.028\right)\left(T_{p}+0.5 T_{a}\right)^{3}+0.6 L^{-0.2}\left\{\left(T_{p}-T_{a}\right) \cos \theta\right\}^{0.25}\right]^{-1}}
$$

The analytical glass cover temperature is calculated by Eq. (18) neglecting temperature drop across the glass cover.

$$
T_{g}=\frac{T_{a}+f T_{p}}{1+f}
$$

The numerical convergence of the total Nusselt number, the loss coefficient of the top and the mean temperature lexan cover on wall 2 is shown in Table 3 for $\theta=45^{\circ}, \mathrm{H}=50 \mathrm{~mm}, h_{w}=25 \mathrm{~W} / \mathrm{m}^{2} \mathrm{~K}, T_{p}=363 \mathrm{~K}$, and $T_{a}=298 \mathrm{~K}$ case. Quadrilateral elements are used because of suitability for the determined models. As a result of the comparisons in Table 2, it is concluded that the number of elements, $200 \times 100 \times 20$, is sufficient. In all cases, solutions were obtained by considering this grid structure.

Table 3. The convergence of the total Nusselt number, top loss coefficient and the lexan cover temperature on wall 2 with the grid configuration for $\theta=45^{\circ}, \mathrm{H}=50 \mathrm{~mm}, h_{w}=25 \mathrm{~W} / \mathrm{m}^{2} \mathrm{~K}, T_{p}=363 \mathrm{~K}, T_{a}=298 \mathrm{~K}$

\begin{tabular}{|c|c|c|c|}
\hline Number of cells & $N u_{t}$ & $U\left(\mathrm{~W} / \mathrm{m}^{2} \mathrm{~K}\right)$ & $T_{g, 2}(\mathrm{~K})$ \\
\hline $100 \times 50 \times 10$ & 39.879 & 7.238 & 319.543 \\
\hline $200 \times 100 \times 20$ & 39.709 & 7.219 & 319.489 \\
\hline $400 \times 200 \times 40$ & 39.666 & 7.214 & 319.475 \\
\hline
\end{tabular}

Comparison of analytical and numerical solutions of the mean temperature between the inner and outer glass cover is given in Figure 2. The analytical and numerically calculated mean glass cover temperature are in perfect agreement.

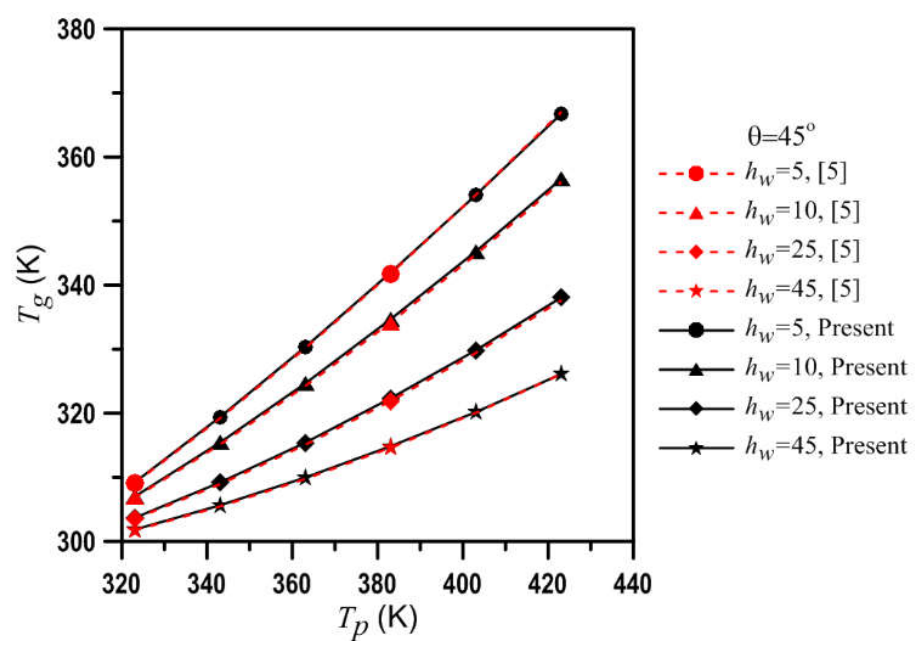

Figure 2. Comparison of the mean temperature of glass cover with analytical [5] and numerical solutions 
For a FPC, the top loss coefficient, $U$, which includes both convection and radiation effects, can be calculated using Eq. (19):

$$
U=\left(\frac{1}{h_{r p g}+h_{c p g}}+\frac{1}{h_{r g a}+h_{w}}+\frac{L_{g}}{k_{g}}\right)^{-1}
$$

where

$$
\begin{aligned}
& h_{r p g}=\frac{q_{r, 2}}{\left(T_{p}-T_{g, 2}\right)} \\
& h_{c p g}=\frac{q_{c, 2}}{\left(T_{p}-T_{g, 2}\right)} \\
& h_{r g a}=\frac{q_{r, 3}}{\left(T_{g, 3}-T_{a}\right)}
\end{aligned}
$$

It assumes that the sky temperature is equal to the external ambient temperature.

\section{RESULTS AND DISCUSSION}

In this study, the combined convective and radiative heat transfer in FPCs filled with a non-participating medium is discussed. The flat-plate solar collector tilt angles are $0^{\circ}$ and $45^{\circ}$. The FPC's are chosen as glass, lexan, and acrylic. The solar collector cover thickness is $\mathrm{L}_{\mathrm{g}}=3.2 \mathrm{~mm}$, while an air gap spacing of $\mathrm{H}=10,25,50$ and $90 \mathrm{~mm}$ is considered.

The isotherms (left) and streamlines (right) of the solar collector covered with lexan for $\theta=0^{\circ}$ and $\theta=45^{\circ}, \mathrm{H}=25 \mathrm{~mm}, h_{w}=25 \mathrm{~W} / \mathrm{m}^{2} \mathrm{~K}, T_{p}=363 \mathrm{~K}$, and $T_{a}=298 \mathrm{~K}$ are shown in Figure 3 . When the tilt angle of the collector is $0^{\circ}$, four counter-rotating flow cells are observed in the air gap.
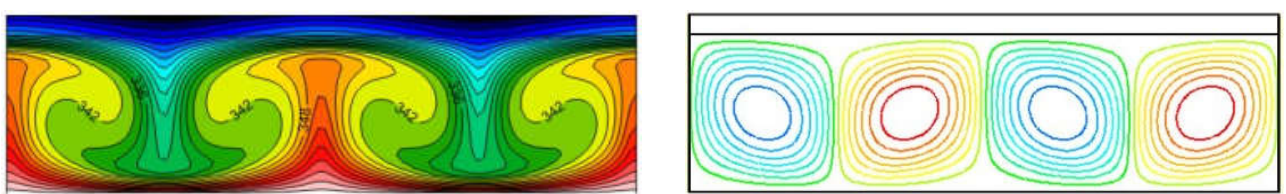

(a)
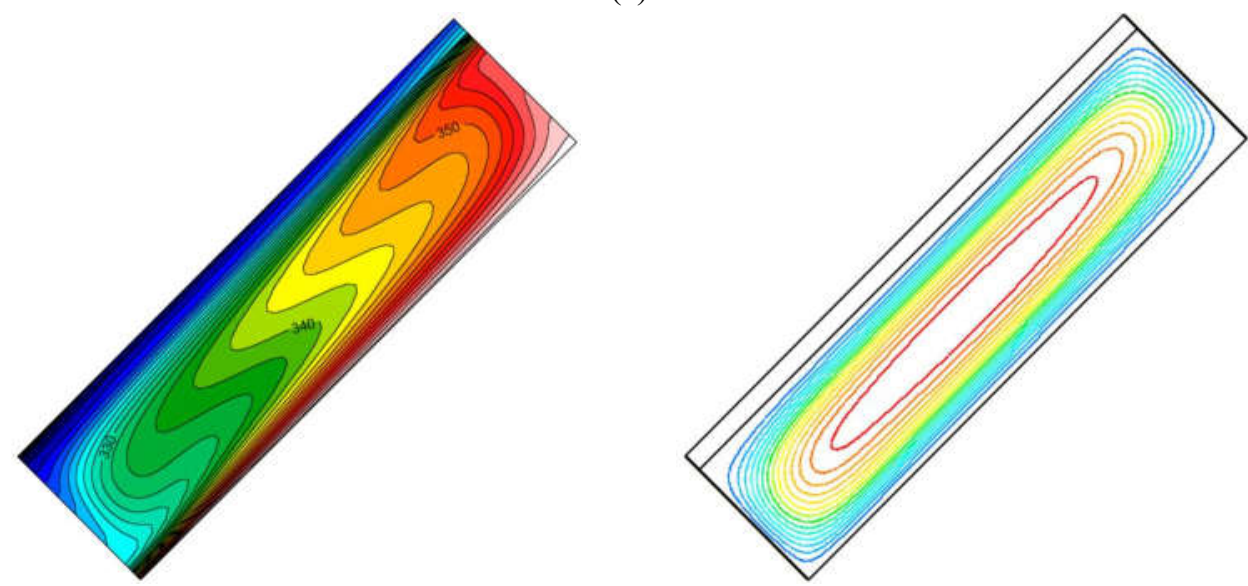

(b)

Figure 3. Isotherms (left) and streamlines (right) of a solar collector with lexan cover for (a) $\theta=0^{\circ}$ and (b) $\theta=45^{\circ}$ 
For $\theta=45^{\circ}$, a single counter-clockwise rotating cell is observed. When the collector is placed in parallel to the side, the density of the heated air from the hot bottom plate falls and rises upwards. The hot air ascends in the form of a chimney through the center of the air gap. Later, the hot air encountering the lexan cover exposed to the cold wall is cooled down and is pushed down symmetrically to the right and to the left (Fig $3 a$ ). For $\theta=45^{\circ}$, the air heated from the hot plate warms up over the hot surface and moves upwards. At the same time, the cold air is pushed down along the lexan cover. Therefore, a single-cell-centric flow occurs counter-clockwise (Fig. $3 b)$.

For the collectors with three different covers, as well as $T_{p}=363 \mathrm{~K}, T_{a}=298 \mathrm{~K}$, the effect on the top loss coefficient of the air gap spacing with the tilt angle and heat transfer coefficient is shown in Figure 4 . The variation of the tilt angle and air gap thickness for the three cover materials results in a change for the top loss coefficient. For all the collector configurations and $\theta=0^{\circ}$, the top loss coefficient increases slightly from $\mathrm{H}=10$ $\mathrm{mm}$ to $\mathrm{H}=25 \mathrm{~mm}$, but decreases slightly by increasing the air gap thickness. For $\theta=45^{\circ}$, the top loss coefficient remains almost unchanged with the air gap thickness for all cover materials (Fig. 4a). In particular, when the wind heat transfer coefficient is small $\left(h_{w}=5 \mathrm{~W} / \mathrm{m}^{2} \mathrm{~K}\right)$, the U-distributions are almost the same (Fig. 4b). However, for $h_{w}=45 \mathrm{~W} / \mathrm{m}^{2} \mathrm{~K}$, the top loss coefficient increases with the air gap spacing by as much as $4 \%$ for all three cover materials when the air spacing gap is increased from $10 \mathrm{~mm}$ to $25 \mathrm{~mm}$ at $h_{w}=45 \mathrm{~W} / \mathrm{m}^{2} \mathrm{~K}$.

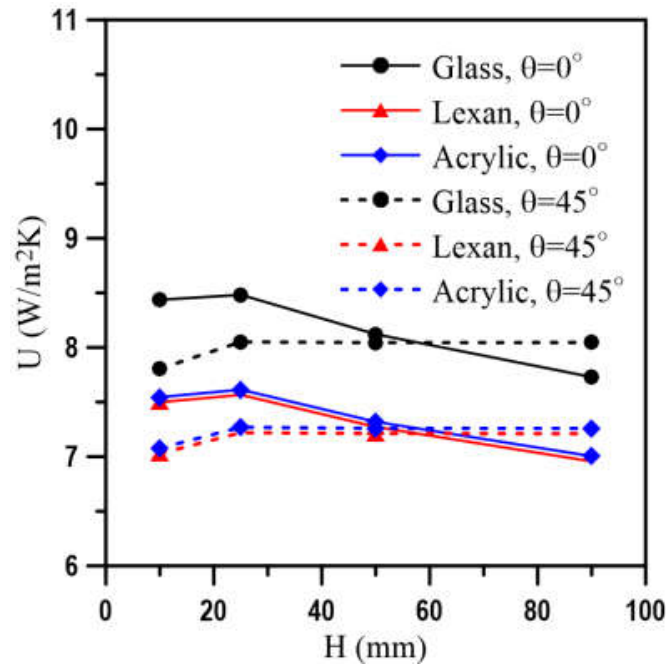

(a)

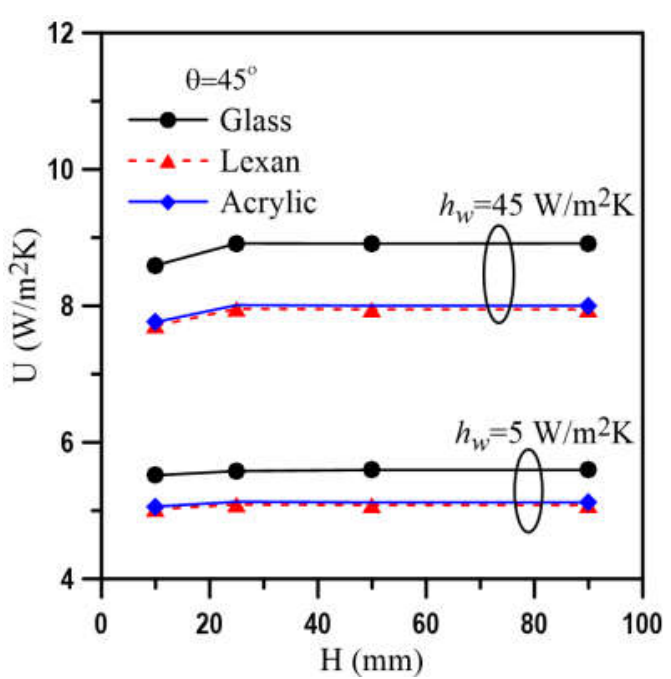

(b)

Figure 4. Variation of top loss coefficient with (a) collector tilt angle and (b) the wind heat transfer coefficient according to air gap spacing for $T_{p}=363 \mathrm{~K}$ and $T_{a}=298 \mathrm{~K}$

The variation of mean cover temperature and top loss coefficient for three different cover materials, $\theta=45^{\circ}$ and $\mathrm{H}=25 \mathrm{~mm}$ are shown in Figure 5 for different heat inputs and wind heat transfer coefficients $\left(h_{w}=5\right.$ and $45 \mathrm{~W} / \mathrm{m}^{2} \mathrm{~K}$ ). As the heat input (bottom plate temperature) increases, the mean cover temperature and top loss coefficient depict an almost linear variation. In addition, since the thermo-physical properties of lexan and acrylic plastic are similar, the mean cover temperature and top loss coefficient are approximately the same. When the wind heat transfer coefficient is low, the mean cover temperature is almost identical. When $h_{w}$ increases, the mean glass cover temperature is lower than that of the plastic. For all $T_{p}$, the top loss coefficient of the glass cover is higher than the plastic cover's top loss coefficient in both heat transfer coefficients. The loss coefficients of the top are similar in the plastic covers. However, with respect to the glass cover, the top loss coefficient $(U)$ is lower. As the top loss coefficient increases, the loss of heat increases from the covers. Therefore, the mean cover temperature decreases. In fact, in $h_{w}=5 \mathrm{~W} / \mathrm{m}^{2} \mathrm{~K}$, the mean cover temperature of the glass is lower than that of the plastic, but as the $h_{w}$ increases, the temperature difference between the plastic and glass covers becomes more pronounced. 


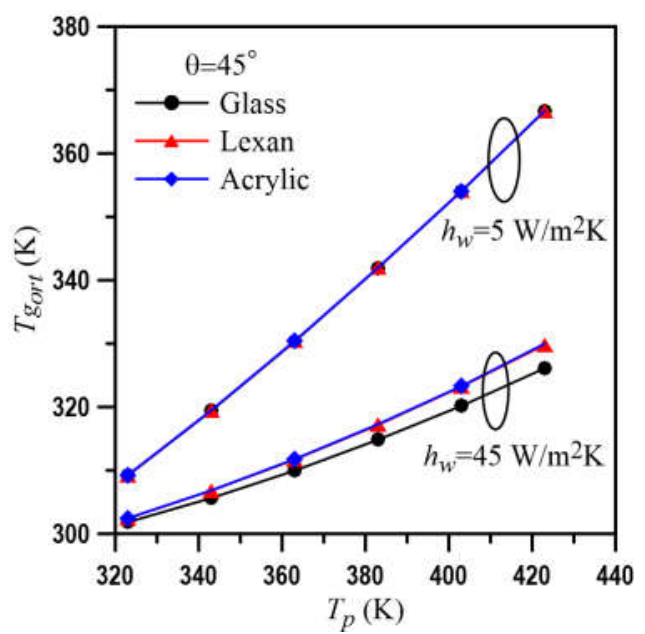

(a)

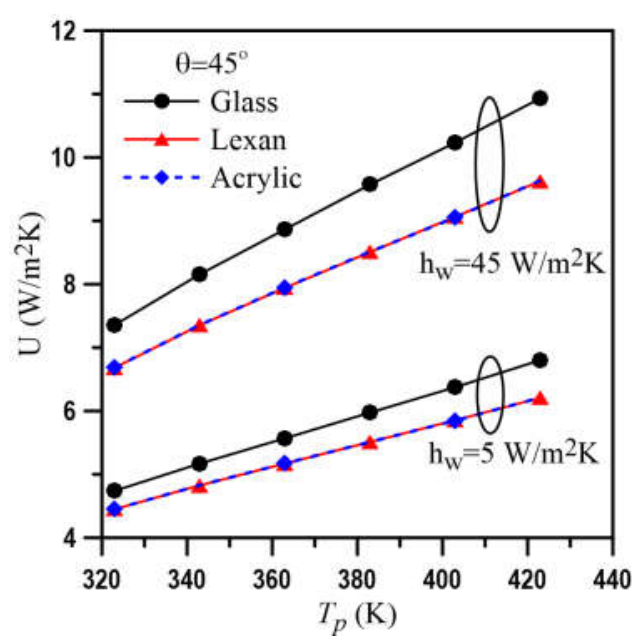

(b)

Figure 5. Variation of (a) mean cover material temperature and (b) top loss coefficient with bottom plate temperature with according to three different covers studied for $h_{w}=5$ and $45 \mathrm{~W} / \mathrm{m}^{2} \mathrm{~K}$

The effect on the top loss coefficient and the mean cover temperature of the external ambient temperature and the bottom plate temperature variation in the solar collector is shown in Figures 6(a) and 6(b) when $\theta=45^{\circ}, h_{w}=25 \mathrm{~W} / \mathrm{m}^{2} \mathrm{~K}$, and $\mathrm{H}=25 \mathrm{~mm}$. Since the thermo-physical properties of plastic cover (lexan and acrylic) are similar, only the effect of the lexan cover collector on the top loss coefficient of the bottom plate temperature is shown in Figure 6(a). Since the thermal conductivity of glass is greater than that of plastic, the heat loss is greater. The top heat loss coefficient of the glass cover with respect to the lexan cover is higher $\approx 11$ $16 \%$. In addition, as the bottom plate temperature and the external ambient temperature increase, the top loss coefficient increases linearly. However, the effect of $T_{p}$ on the top loss coefficient is greater than that of $T_{a}$. When the $T_{p}$ temperature is increased from $323 \mathrm{~K}$ to $423 \mathrm{~K}$, there is approximately a $42 \%$ increase in the top loss coefficient in both cover materials. The increase in the top loss coefficient with increasing $T_{a}$ is around 1-4\%. As can be seen from Figure $6 \mathrm{~b}$, the effect of $T_{a}$ on $T_{g}$ is negligible.

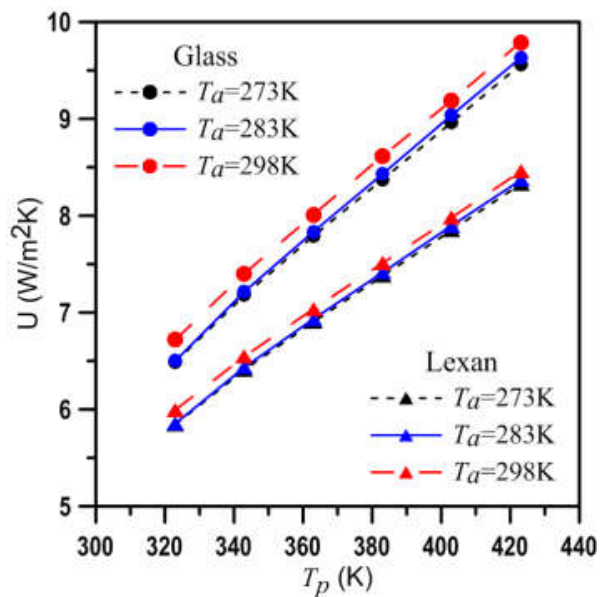

(a)

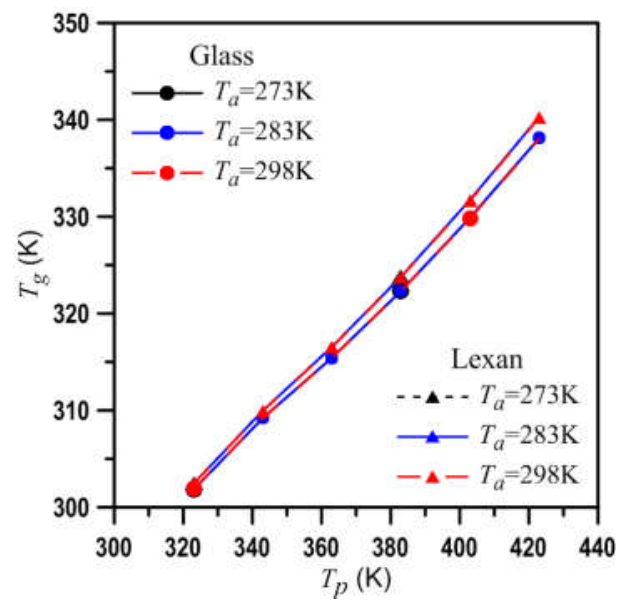

(b)

Figure 6. Effect of external ambient temperature and bottom plate temperature on (a) top loss coefficient and (b) mean cover temperature

The mean convection, radiation and total Nusselt numbers of three different covers for $h_{w}=5$ and 45 $\mathrm{W} / \mathrm{m}^{2} \mathrm{~K}$ are shown in Figure 7 for $\mathrm{H}=25 \mathrm{~mm}, T_{a}=298 \mathrm{~K}$, and $\theta=45^{\circ}$. The increase in the mean convection Nusselt number was more pronounced at the bottom plate for the temperature range of $323-383 \mathrm{~K}$, while this increase is smaller for $383-423 \mathrm{~K}$. 


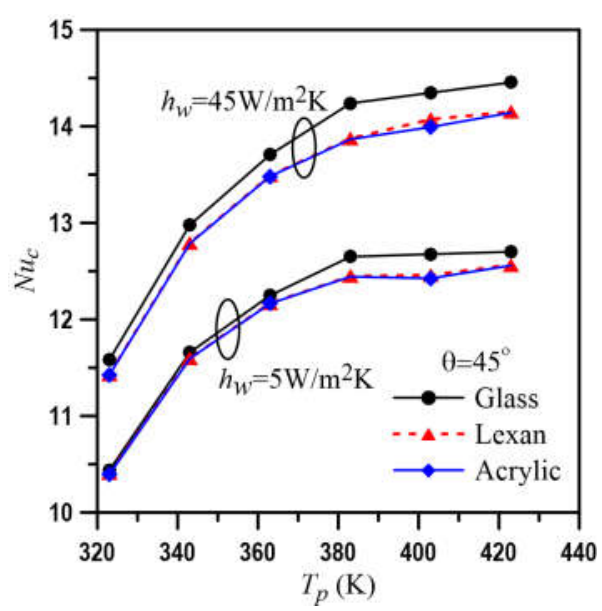

(a)

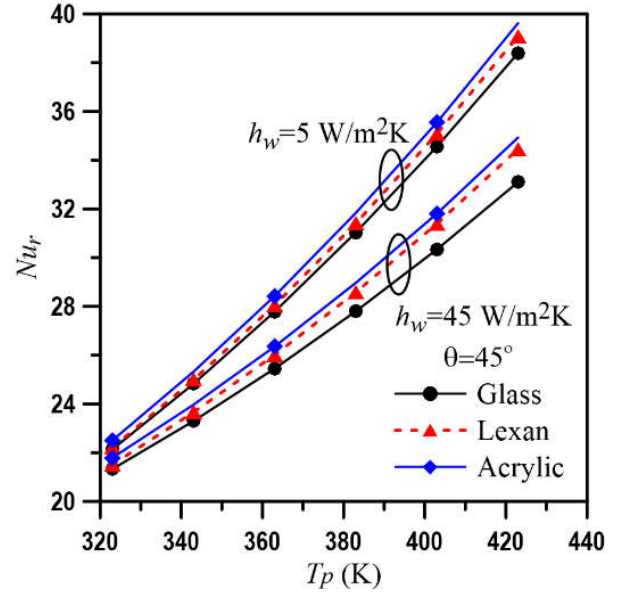

(b)

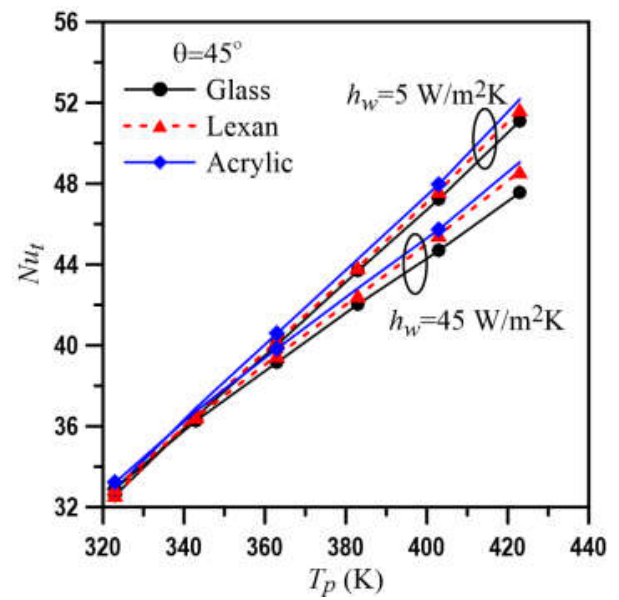

(c)

Figure 7. Variation of $N u_{c}, N u_{r}$ and $N u_{t}$ with bottom plate temperature according to three different covers for $h_{w}=5$ and $45 \mathrm{~W} / \mathrm{m}^{2} \mathrm{~K}$

The mean convection Nusselt number increases with an increasing wind heat transfer coefficient. In addition, the mean $N u_{c}$ of the glass cover is higher than the other plastic covers, because the thermal conductivity of glass is high. $N u_{r}$ and $N u_{t}$ are found to increase linearly with increasing $T_{p}$ value in both $h_{w}=5$ and $45 \mathrm{~W} / \mathrm{m}^{2} \mathrm{~K}$. For small values of $T_{p}$, the change in the cover material and the heat transfer coefficient does not affect $N u_{t}$. For $T_{p}$ is greater than $383 \mathrm{~K}$, the change in the heat transfer coefficient and the cover material affect $N u_{t}$. For $h_{w}=5$ and $45 \mathrm{~W} / \mathrm{m}^{2} \mathrm{~K}$, maximum $N u_{t}$ and $N u_{r}$, arranged in ascending order, are acrylic, lexan and glass.

\section{CONCLUDING REMARKS}

The main conclusions of the study can be summarized as follows:

- Variations are observed in isotherms and streamlines as the collector tilt angle is changed. When the collector is situated horizontally (zero tilt angle), more than one circulation cell is formed in the air spacing gap, but for $\theta=45^{\circ}$ a rotating single-cell fills the gap. However, no changes are observed in the isotherms and streamlines with the use of different cover materials.

- As $T_{p}$ increases, $U$ and $T_{g}$ increase linearly, but with an increase of $T_{a}, U$ and $T_{g}$ remain unchanged.

- As the thermo-physical properties of lexan and acrylic plastic covers are similar, the top heat loss coefficients are identical. The $U$ value of glass covers is higher than that for plastic covers.

- At low heat transfer coefficient $\left(h_{w}=5 \mathrm{~W} / \mathrm{m}^{2} \mathrm{~K}\right), T_{g}$ for the three types of cover is extremely close to each other. With increasing heat transfer coefficient $\left(h_{w}=45 \mathrm{~W} / \mathrm{m}^{2} \mathrm{~K}\right)$, the $T_{g}$ in the glass cover material is less than for the plastic covers. 
- All mean Nusselt numbers increased with increasing $T_{p}$. However, $N u_{t}$ and $N u_{r}$ are linear in all $T_{p}$. While $T_{p}$ is between 323 and $383 \mathrm{~K}, N u_{c}$ increases almost linearly. However, for $T_{p}$ higher than $383 \mathrm{~K}$, the amount of $N u_{c}$ exchange decreases.

- In the cover material where the heat loss is greatest, the use of plastic cover material is more advantageous than using glass cover material.

\section{NOMENCLATURE}

$c_{p} \quad$ Specific heat of air, $\mathrm{J} / \mathrm{kg} \mathrm{K}$

$c_{p_{g}} \quad$ Specific heat of cover material, $\mathrm{J} / \mathrm{kg} \mathrm{K}$

$f \quad$ The ratio of outer to inner thermal resistance

$\mathrm{H} \quad$ Air gap spacing, $\mathrm{m}$

$h_{w} \quad$ Wind heat transfer coefficient, $\mathrm{W} / \mathrm{m}^{2} \mathrm{~K}$

$h_{r p g} \quad$ Radiative heat transfer coefficient between absorber plate and cover, $\mathrm{W} / \mathrm{m}^{2} \mathrm{~K}$

$h_{\text {cpg }} \quad$ Convective heat transfer coefficient between absorber plate and cover, $\mathrm{W} / \mathrm{m}^{2} \mathrm{~K}$

$h_{\text {rga }} \quad$ Radiative heat transfer coefficient between cover and surrounding, $\mathrm{W} / \mathrm{m}^{2} \mathrm{~K}$

G Incident energy, $\mathrm{W} / \mathrm{m}^{2}$

g Acceleration due to gravity, $\mathrm{m} / \mathrm{s}^{2}$

$I(s, \mathbf{s}) \quad$ Radiation intensity in spatial position $s$ and directions, $\mathrm{W} / \mathrm{m}^{2}$

$I_{b} \quad$ Blackbody radiation intensity, $\mathrm{W} / \mathrm{m}^{2} \mathrm{sr}$

$I_{\text {in }} \quad$ Incoming radiation intensity, $\mathrm{W} / \mathrm{m}^{2}$

$I_{p} \quad$ Radiation intensity outgoing from the absorber plate, $\mathrm{W} / \mathrm{m}^{2}$

$I_{2, a} \quad$ Radiation intensity on side air of the interface wall-2, W/m ${ }^{2}$

$I_{2, g} \quad$ Radiation intensity on side cover of the interface wall-2, W/m ${ }^{2}$

$k \quad$ Thermal conductivity of air, $\mathrm{W} / \mathrm{mK}$

$k_{g} \quad$ Thermal conductivity of cover, W/Mk

$\mathrm{L} \quad$ Length of flat plate collector, $\mathrm{m}$

$\mathrm{L}_{\mathrm{g}} \quad$ Solar collector cover thickness, $\mathrm{m}$

$n \quad$ Refractive index ratio, $\mathrm{n}_{\mathrm{g}} / \mathrm{n}_{a}$

$n_{a} \quad$ Refractive index of air

$n_{g} \quad$ Refractive index of cover

$\mathrm{Nu} \quad$ Mean Nusselt number

$N u_{r, 2} \quad$ Radiation Nusselt number of wall 2

$N u_{c, 2} \quad$ Convection Nusselt number of wall 2

$N u_{r, 3} \quad$ Radiation Nusselt number of wall 3

$P \quad$ Pressure [Pa]

Pr Prandtl number $[=v / \alpha]$

$q \quad$ Heat flux, $\mathrm{W} / \mathrm{m}^{2}$

$q_{i n, a} \quad$ Heat flux on side air of the interface wall-2, W/m $\mathrm{m}^{2}$

$q_{i n, g} \quad$ Heat flux on side cover of the interface wall-2, W/ $/ \mathrm{m}^{2}$

$\mathrm{q}_{\mathrm{c}, 2} \quad$ Convective heat flux of wall-2, $\mathrm{W} / \mathrm{m}^{2}$

$\mathrm{q}_{\mathrm{r}, 2} \quad$ Radiative heat flux of wall-2, $\mathrm{W} / \mathrm{m}^{2}$

$\mathrm{q}_{\mathrm{r}, 3} \quad$ Radiative heat flux of wall- $3, \mathrm{~W} / \mathrm{m}^{2}$

r Position vector

$\mathrm{r}_{2} \quad$ Hemispherical average reflectivity of wall-2

$\mathrm{r}_{2, \mathrm{a}} \quad$ Hemispherical average reflectivity on side air of interface wall-2

$r_{2, g} \quad$ Hemispherical average reflectivity on side cover of interface wall-2

s Direction vector

s' $\quad$ Scattering direction vector

$T \quad$ Temperature, $\mathrm{K}$ 


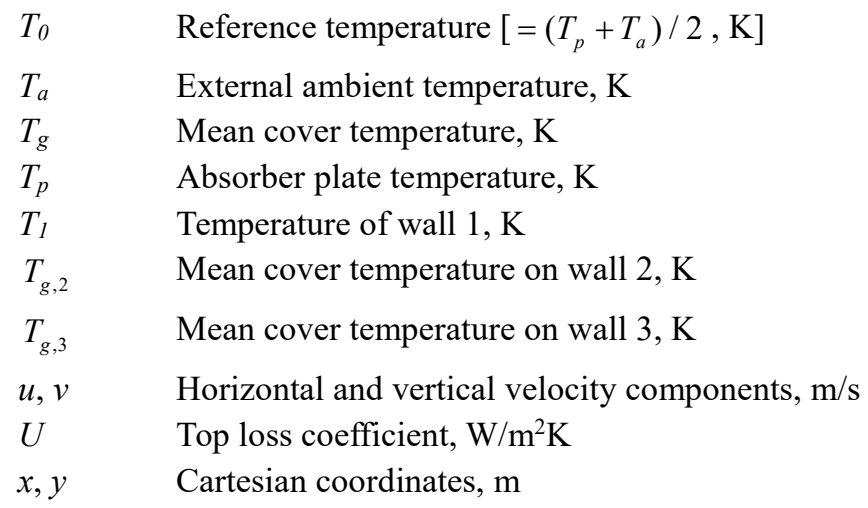

Greek symbols

$\begin{array}{ll}\alpha & \text { Thermal diffusivity, } \mathrm{m} / \mathrm{s}^{2} \\ \beta & \text { Coefficient of thermal expansion, } 1 / \mathrm{K} \\ \Delta T & \text { Temperature difference, } \mathrm{K} \\ \varepsilon & \text { Surface emissivity } \\ \theta & \text { Solar collector tilt angle, } \\ v & \text { Kinematic viscosity, } \mathrm{m}^{2} / \mathrm{s} \\ \kappa & \text { Absorption coefficient, } 1 / \mathrm{m} \\ \rho & \text { Density of air, } \mathrm{kg} / \mathrm{m}^{3} \\ \rho_{g} & \text { Density of solar collector cover, } \mathrm{kg} / \mathrm{m}^{3} \\ \sigma & \text { Stefan Boltzmann constant, W/m } / \mathrm{K}^{4} \\ \sigma_{s} & \text { Scattering coefficient, } 1 / \mathrm{m} \\ \tau_{2, a} & \text { Transitivity on side air of the interface wall-2, } \mathrm{W} / \mathrm{m}^{2} \\ \tau_{2, g} & \text { Transitivity on side cover of the interface wall }-2, \mathrm{~W} / \mathrm{m}^{2} \\ \Phi & \text { Phase function } \\ \Omega^{\prime} & \text { Solid angle }\end{array}$

\section{Subscripts}

$\begin{array}{ll}1,2,3 & \text { Wall number (wall 1, wall 2, wall 3) } \\ c & \text { Convection } \\ g & \text { Cover } \\ r & \text { Radiation } \\ t & \text { Total } \\ \mathrm{w} & \text { Wall }\end{array}$

$\begin{array}{ll}\text { Abbreviations } \\ \text { DOM } & \text { Discrete Ordinates Method } \\ \text { FVM } & \text { Finite Volume Method } \\ \text { FPC } & \text { Flat Plate Collector } \\ \text { PSC } & \text { Plastic Solar Collector } \\ \text { RTE } & \text { Radiative Transfer Equation }\end{array}$

\section{REFERENCES}

[1] Addeo, A., Campanile, G., Nicolais, L., Romeo, G. Plastic solar collectors for 'low energy' applications. Appl Energ 1980; 6(4): 265-74. https://doi.org/10.1016/0306-2619(80)90017-3.

[2] Sodha, M., Bansal, N. K., Singh, D. Analysis of a black liquid flat plate solar collector. Int J Energ Res 1984; 8(1): 31-7. https://doi.org/10.1002/er.4440080104.

[3] Bansal, N. K., Kumar, A., Singh, S. P. Thermal performance of plastic film solar air and water heaters. Int J Energ Res 1987; 11(1): 35-43. https://doi.org/10.1002/er.4440110104.

[4] Van Niekerk, W. V., Scheffler, B. Measured performance of a solar water heater with a parallel tube 

Akhtar, N., Mullick, S. C. Approximate method for computation of glass cover temperature and top heatloss coefficient of solar collectors with single glazing. Sol Energy 1999; 66(5): 349-54. https://doi.org/10.1016/S0038-092X(99)00032-8.

[6] Akhtar, N., Mullick, S. C. Effect of absorption of solar radiation in glass-cover(s) on heat transfer coefficients in upward heat flow in single and double glazed flat-plate collectors. Int J Heat Mass Tran 2012; 55(1-3): 125-32. https://doi.org/10.1016/j.ijheatmasstransfer.2011.08.048.

[7] Kumar, S., Mullick, S. C. Glass cover temperature and top heat loss coefficient of a single glazed flat plate collector with nearly vertical configuration. Ain Shams Eng J 2012; 3(3): 299-304. https://doi.org/10.1016/j.asej.2012.03.008.

[8] Samdarshi, S. K., Mullick, S. C. Analytical equation for the top heat loss factor of a flat-plate collector with double glazing. J Sol Energy Eng 1991; 113(2): 117-22. https://doi.org/10.1115/1.2929955.

[9] Ferahta, F. Z., Bougoul, S., Ababsa, D., Abid, C. Numerical study of the convection in the air gap of a solar collector. Enrgy Proced 2011; 6(2011): 176-84. https://doi.org/10.1016/j.egypro.2011.05.021.

[10] Subiantoro, A., Tiow, O. K. Analytical models for the computation and optimization of single and double glazing flat plate solar collectors with normal and small air gap spacing. Appl Energ 2013; 104: 392-99. https://doi.org/10.1016/j.apenergy.2012.11.009.

[11] Kumar, S., Mullick, S. C. Wind heat transfer coefficient in solar collectors in outdoor conditions. Sol Energy 2010; 84(6): 956-63. https://doi.org/10.1016/j.solener.2010.03.003.

[12] Hematian, A., Bakhtiari, A. A. Efficiency analysis of an air solar flat plate collector in different convection modes. Int J Green Energy 2015; 12(9): 881-7. doi: 10.1080/15435075.2014.940621.

[13] Wu, S. Y., Zhang, H., Xiao, L., Qiu, Y. Experimental investigation on convection heat transfer characteristics of flat plate under environmental wind condition. Int J Green Energy 2016; 14(3): 317-29. https://doi.org/10.1080/15435075.2016.1259164.

[14] Stanciu, C., Stanciu, D. Optimum tilt angle for flat plate collectors all over the World - A declination dependence formula and comparisons of three solar radiation models. Energ Convers Manage 2014; 81: 133-43. https://doi.org/10.1016/j.enconman.2014.02.016.

[15] Jiandog, Z., Hanzhong, T., Susu, C. Numerical simulation for structural parameters of flat-plate solar collector. Sol Energy 2015; 117: 192-202. doi: 10.1016/j.solener.2015.04.027.

[16] Aravindh, M. A., Sreekumar, A. Efficiency enhancement in solar air heaters by modification of absorber plate-A Review. Int J Green Energy 2016; 13(12): 1209-23. doi:10.1080/15435075.2016.1183207.

[17] Jannot, Y., Coulibaly, Y. Radiative heat transfer in a solar air heater covered with a plastic film. Sol Energy 1997; 60(1): 35-40. doi:10.1016/S0038-092X(96)00145-4.

[18] Khoukhi, M., Maruyama, S. Theoretical approach of a flat-plate solar collector taking into account the absorption and emission within glass cover layer. Sol Energy 2006; 80(7): 787-94. https://doi.org/10.1016/j.renene.2004.09.014.

[19] El-Sebaii, A.A., Al-Snani, H. Effect of selective coating on thermal performance of flat plate solar air heaters. Energy 2010; 35: 1820-8. https://doi.org/10.1016/j.energy.2009.12.037.

[20] Alghoul, M. A., Sulaiman, M.Y., Azmi, B.Z., Wahab, M.Abd. Review of materials for solar thermal collectors. Anti-Corrosion Methods and Materials 2005; 52(4): 199-206. doi: 10.1108/00035590510603210.

[21] Giovannetti, F., Foste, S., Ehrmann, N., Rockendorf, G. High transmittance, low emissivity glass covers for flat plate collectors: Applications and performance. Sol Energy 2014; 104: 52-9. https://doi.org/10.1016/j.solener.2013.10.006.

[22] Otanicar, T.P., Phelan, P.E., Prasher, R.S., Rosengarten, G., Taylor, R.A. Nanofluid-Based direct absorption solar collector. J Renew Sustain Ener 2010; 2(3): 1-13. https://doi.org/10.1063/1.3429737.

[23] Karami, M., Bahabadi, M.A., Delfani, S., Ghozatloo, A. A new application of carbon nanotubes nanofluid as working fluid of low-temperature direct absorption solar collector. Sol Energ Mat Solar C 2014; 121: 114-118. https://doi.org/10.1016/j.solmat.2013.11.004.

[24] Ahlatli, S., Mare, T., Estelle, P., Doner, N. Thermal performance of carbon nanotube nanofluids in solar microchannel collectors: An Experimental Study. Int J Techn 2016 (2), 219-226. doi: 10.14716/ijtech.v7i2.1575

[25] Roy, S., Asirvatham, L. G., Kunhappan, D., Cephas, E., Wongwises, S. Heat Transfer Performance of Silver/Water. J Therm Eng 2015; 1 (2): 104-12. doi: 10.18186/jte.29475.

[26] Hussein, A. K., Walunj, A. A., Kolsi, L. Applications of Nanotechnology to Enhance the Performance of the Direct Absorption Solar Collectors. J Therm Eng 2016; 2 (1): 529-40. doi:10.18186/jte.46009.

[27] M. Modest. Radiative heat transfer. New York: McGraw-Hill Press; 1993.

[28] Fluent Inc. FLUENT 6.1 User's Guide. Lebanon: NH; 2003.

[29] O'Brien-Bernini, F.C., McGowan, J.G. Performance modeling of non-metallic flat plate solar collectors. Sol Energy 1984; 33: 305-19. https://doi.org/10.1016/0038-092X(84)90161-0. 
Journal of Thermal Engineering, Research Article, Vol. 6, No. 5, pp. 829-842, October, 2020

[30] Genc, A.M., Ezan, M.A., Turgut, A. Thermal performance of a nanofluid-based flat plate solar collector: a transient numerical study. Appl Therm Eng 2018; 130: 395-407. https://doi.org/10.1016/j.applthermaleng.2017.10.166.

[31] http://www.matweb.com/index.aspx. (Data sheets for over 125000 metals, plastics, ceramics, and composites.) 